\title{
Role of subconcussion in repetitive mild traumatic brain injury
}

\author{
A review \\ Julian E. Bailes, M.D., ${ }^{1}$ Anthony L. Petraglia, M.D., ${ }^{2}$ \\ Bennet I. Omalu, M.D., M.B.A., M.P.H., ${ }^{3}$ Eric Nauman, Ph.D., ${ }^{4,5}$ \\ and Thomas Talavage, Ph.D. \\ ${ }^{I}$ Department of Neurosurgery, NorthShore University Health System, University of Chicago Pritzker School \\ of Medicine, Evanston, Illinois; ${ }^{2}$ Department of Neurosurgery, University of Rochester Medical Center, \\ Rochester, New York; ${ }^{3}$ Department of Pathology, University of California, Davis, California; ${ }^{4}$ School of \\ Mechanical Engineering; ${ }^{5}$ Weldon School of Biomedical Engineering; and ${ }^{6}$ School of Electrical and \\ Computer Engineering, Purdue University, West Lafayette, Indiana
}

\begin{abstract}
Research now suggests that head impacts commonly occur during contact sports in which visible signs or symptoms of neurological dysfunction may not develop despite those impacts having the potential for neurological injury. Recent biophysics studies utilizing helmet accelerometers have indicated that athletes at the collegiate and high school levels sustain a surprisingly high number of head impacts ranging from several hundred to well over 1000 during the course of a season. The associated cumulative impact burdens over the course of a career are equally important. Clinical studies have also identified athletes with no readily observable symptoms but who exhibit functional impairment as measured by neuropsychological testing and functional MRI. Such findings have been corroborated by diffusion tensor imaging studies demonstrating axonal injury in asymptomatic athletes at the end of a season. Recent autopsy data have shown that there are subsets of athletes in contact sports who do not have a history of known or identified concussions but nonetheless have neurodegenerative pathology consistent with chronic traumatic encephalopathy. Finally, emerging laboratory data have demonstrated significant axonal injury, blood-brain barrier permeability, and evidence of neuroinflammation, all in the absence of behavioral changes. Such data suggest that subconcussive level impacts can lead to significant neurological alterations, especially if the blows are repetitive. The authors propose "subconcussion" as a significant emerging concept requiring thorough consideration of the potential role it plays in accruing sufficient anatomical and/or physiological damage in athletes and military personnel, such that the effects of these injuries are clinically expressed either contemporaneously or later in life.
\end{abstract}

(http://thejns.org/doi/abs/10.3171/2013.7.JNS121822)

\section{KEY WoRDS • chronic traumatic encephalopathy • concussion • mild traumatic brain injury $\bullet$ postconcussive syndrome $\bullet$ sports $\bullet$ subconcussion}

$\mathrm{T}$ HERE has been growing interest in the diagnosis and management of mild traumatic brain injury, or concussion. Clinical care of athletes with concussion has traditionally centered on recognizing signs and symptoms associated with a concussive event. Over the last 2 decades, the cataloging of concussive manifestations into tiered grading scales has allowed identification and ultimate management of those injured, to guide their proper recovery and safe return to participation in their sport. But these grading scales have largely been replaced by recognizing

Abbreviations used in this paper: $\mathrm{COI}+=$ presence of clinically observed impairment; COI- = absence of COI; CTE = chronic traumatic encephalopathy; fMRI = functional MRI; FOI $+=$ presence of functionally observed impairment; FOI $-=$ absence of FOI; LOC $=$ loss of consciousness; $\mathrm{mTBI}=$ mild traumatic brain injury; $\mathrm{NFL}=$ National Football League; TBI = traumatic brain injury . and characterizing concussion symptoms and their duration to determine the severity of head injury. It has been recognized that sports concussion is associated with LOC in a minority of patients (10\%) and that other symptoms, such as confusion, amnesia, dizziness, visual disturbances, and headache, are more characteristic. ${ }^{48,65}$ Additionally, appropriate management is centered on a symptom-free waiting period of physical and cognitive rest, to allow the athlete to usually return to subsequent play.

Emerging evidence now suggests that head impacts commonly occur during contact or collision sports in which symptoms may not develop and there are no outward or visible signs of neurological dysfunction. These impacts are often not recognized or identified as a concussion at the clinical level. This evidence includes biophysics data, advanced neuroimaging findings, and forensic analyses of the brains of former football players who did not 
have a diagnosis of concussion during their playing career, as well as the brains of laboratory animals subjected to mild traumatic forces.

Subconcussion is a cranial impact that does not result in known or diagnosed concussion on clinical grounds. It can also occur with rapid acceleration-deceleration of the body or torso, particularly when the brain is free to move within the cranium, creating a "slosh" phenomenon. ${ }^{77}$ Subconcussion has its greatest effect through repetitive occurrences whereby cumulative exposure becomes deleterious.

The concept of minimal or subconcussive injuries thus requires examination and consideration of the role they may play in accruing sufficient anatomical and/or physiological damage, such that the effects of these injuries are potentially expressed later in life. Our purpose in this narrative review was to provide an organized, comprehensive overview of the available evidence supporting the concept of subconcussion. Additionally, we emphasized that subconcussion is a previously underrecognized phenomenon that needs further exploration and contemporaneous appreciation of its ability to cause significant current and future detrimental neurological effects.

\section{Methods}

The primary means of identifying studies to be included in our review was an electronic search of the English literature from 1900 to 2011 using various search engines, including MEDLINE, PubMed, Google Scholar, and the Cochrane Database. Initially, potential articles were identified using a combination of the following search terms: "subconcussion," "subconcussive head injury," "concussion," "mild traumatic brain injury," "TBI," "animal models," "repetitive traumatic brain injury," "pathophysiology," "chronic traumatic encephalopathy," "neurodegeneration," "head impacts," "accelerometer," "neuropsychology," "neuroimaging," "magnetic resonance imaging," "functional magnetic resonance imaging," and "diffusion tensor imaging." The abstracts of the various retrieved studies were screened, and the clinical and laboratory studies that focused on subconcussion or head injuries and/or impacts in which no concussion was diagnosed were chosen for inclusion in this narrative review. The associated medical subheadings (MeSH) for each database were used preferentially, when provided. In addition, any relevant references from the evaluated literature were searched and included in the review to ensure a thorough capture of the literature.

\section{Results}

\section{Laboratory Evidence of Subconcussive Effects}

Traumatic brain injury is traditionally thought to involve both primary and secondary injury phases. The primary injury is represented by the moment of impact, resulting from the translation of kinetic energy and force vectors in a linear acceleration-deceleration mechanism, through a rotational mechanism, or a combination of both..$^{22}$ Secondary injury is the indirect result of the trauma and its subsequent pathophysiological processes and includes both immediate and delayed cellular events. ${ }^{22}$ In addition to primary and secondary injury, the concept of a tertiary phase of TBI may now be thought of as ongoing abnormalities in glucose utilization and cellular metabolism as well as membrane fluidity, synaptic function, and structural integrity. $3,35,43-45,66,67,71,78$ This phase of TBI may become chronic and compounded if the individual is subjected to repetitive minor head impacts.

There may be immediate and delayed cellular events, which can include ionic shifts, disturbances in calcium channels, ATP pump failure, and mitochondrial perturbations resulting in neurological dysfunction and the potential for cell death through apoptotic pathways. ${ }^{54} \mathrm{In} \mathrm{mTBI}$, cellular metabolism is disturbed, ultrastructural damage can occur, and both biochemical and vascular autoregulation abnormalities may be involved.

In essence, axonal membranes are injured and axonal transport is interrupted in a progressive process. This concept is supported by recent autopsy findings in professional contact-sport athletes who demonstrate multifocal areas of damaged neurons and their processes, remarkable for tau protein antibody staining, representing a temporal and spatial pattern of repetitive injury. ${ }^{6,27,49,57,59-63}$ In addition, a recently proposed theory suggests that chronic inflammation may occur, based in large part upon the activation of microglia, leading to a cascade of deleterious effects. ${ }^{9}$

Little attention was paid to repetitive mild head injury before the year 2000 , with just a few repetitive injury studies being published. ${ }^{36,56,87}$ Since then, there has been increased interest in laboratory research focused on repetitive mTBI. ${ }^{1,8,14,17,23,25,37,40,42,69,74,82,88}$ Most of these studies were performed in rodents, with a few performed in pig models of TBI. In one study, DeFord et al. showed that as compared with a single episode of mTBI, repeat injury was associated with impairments in complex spatial learning and cognitive impairment ${ }^{23}$ - this despite no overt cell death in the cortex or hippocampus or bloodbrain barrier compromise.

Kanayama et al. demonstrated that repetitive mTBI causes changes in cortical and hippocampal cytoskeletal proteins, whereas a single injury does not. ${ }^{36}$ Laurer et al. showed that a second injury induces both local and regional changes in the cerebral cortex. ${ }^{40}$ Given their results, these authors suggested that the brain has an increased vulnerability to a second traumatic insult for at least 24 hours following an initial episode of mild brain trauma. Another study used microtubule-associated protein-2 staining techniques to demonstrate that local and remote injuries are significantly greater if they occur in a shorter time window following an initial injury in mice, which exhibited minimal behavioral response following head impact. ${ }^{42}$ Some of these studies also documented evidence of CNS injury despite no overt behavioral deficits, which is consistent with subconcussive injury.

Some researchers have demonstrated evidence of deleterious effects following a single subconcussive experimental head injury. By modifying the Marmarou weight-drop model of concussion, we have been able to diminish impact forces to effect no obvious reaction or behavior change, and thus simulating less than a concussive 
injury. ${ }^{2,51-53}$ Using staining for amyloid precursor protein, we have shown that these subconcussive impacts reliably produce tearing of axons and the formation of axonal retraction bulbs in the brainstem-level descending motor pathways. In reducing the fall height of a $450 \mathrm{-g}$ mass from 2 to $1 \mathrm{~m}$, we found no alteration of consciousness or responsiveness but significant numbers of amyloid precursor protein-positive axons compared with the number in controls (JD Mills, JE Bailes, unpublished data, 2010).

In a fluid-percussion brain injury model in rats, Lifshitz and Lisembee found at 28 days that thalamic ventral basal neurons exhibit atrophic changes without neuronal death. ${ }^{41}$ Persistence in a chronic atrophic state after ipsilateral hippocampal injury was noted to deprive the deafferentated basal cholinergic neurons of trophic support, a finding consistent with detailed autopsy studies on athletes with CTE. ${ }^{59-63}$ In one vertical-impact model of mTBI in rodents, the authors found that there was minimal change in the animals' behavioral response following injury; however, at euthanization, the animals showed dark, swollen neuronal soma. ${ }^{39}$ Creed et al. showed that compared with sham-injured mice, the mice with concussive brain injuries had abnormal spatial acquisition and working memory as measured by the Morris water maze over the first 3 days $(p<0.001)$ but not later than the 4th day postinjury. ${ }^{16}$ At 1 and 3 days postinjury, intraaxonal accumulation of amyloid precursor protein in the corpus callosum and cingulum was associated with neurofilament dephosphorylation, abnormal transport of FluoroGold and synaptophysin, and deficits in axonal conductance, which continued until 14 days postinjury when axonal degeneration was apparent. Although there may be recovery from acute cognitive deficits, this model showed that even subconcussive brain trauma leads to axonal degeneration and abnormal axonal function. ${ }^{16}$

Shultz et al. investigated the effects of a mild lateral fluid-percussion injury (0.50-0.99 atm) on rat behavior and neuropathological changes in an attempt to better understand subconcussive brain injury. ${ }^{75}$ In their study, male Long-Evans rats received either a single mild lateral fluidpercussion injury or a sham injury, followed by either a short ( 24 hours) or a long ( 4 weeks) recovery period. No significant group differences were found in behavioral and axonal injury measures; however, the rats given one subconcussive mild fluid-percussion injury displayed a significant increase in microglial activation and reactive astrogliosis at 4 days postinjury. ${ }^{75}$ The authors inferred that this result was consistent with an acute neuroinflammatory response. Chronic neuroinflammation is a mechanism with the potential to contribute to the cumulative and neurodegenerative effects of repeated subconcussive injuries, and these findings are consistent with those in humans experiencing a subconcussive impact. ${ }^{975}$

\section{Clinical Evidence of Subconcussion}

Biophysics Data. In most cases of head injury there are components of both linear and angular forces at work. It is important to remember the variables in play that determine the kinetic energy imparted by these forces (kinetic energy $=1 / 2 \mathrm{mv}^{2}$ ). Modern-day athletes are bigger, stronger, and faster. Interestingly, neck-strengthening exercises and increasing the mass of the head-neck segment have been suggested as means of possibly reducing the incidence of concussion or subconcussion; however, no definitive evidence has proven that neck strengthening plays a role in concussion prevention. Increased neck strength (not just mass) may diffuse the forces imparted in a head impact or may limit the cranial excursion and brain movement inside the skull (slosh) ${ }^{77}$ Neck strength may be particularly important at the junior and youth athletic levels and in female athletes. ${ }^{4,5,15,81}$ In general, modern players have amassed a greater total size (mass), thus increasing the kinetic energy imparted in blows to the head. Moreover, during the past several decades, the velocities of impacts have increased and are probably the single greatest factor in the apparent rise in concussion incidence. In actuality, it is the change in velocity, through acceleration and deceleration, that relates to the energy transmitted to the player's body and brain. ${ }^{22}$

Concussion and subconcussion can occur in any sport; however, American football has a high incidence of concussion, largely because of the style of play, high rate of impacts, and extent of participation. ${ }^{34}$ The mandatory use of helmets in American football has allowed for the systematic analysis of injury biomechanics and real-time measurements of forces, velocities, accelerations, and frequencies of head impacts by using implanted telemetry devices. In addition, studies organized by the NFL have included detailed computerized video analysis of actual game film in 182 concussive and subconcussive hits that occurred between 1996 and 2001.64 These impacts were then modeled or reenacted in a laboratory setting using crash test dummies. These studies showed that the highest strain forces were imparted to the deep midbrain level near the head's center of gravity, occurring $10 \mathrm{msec}$ following impact. The researchers postulated that the forces imparted to the mesencephalon, corpus callosum, and fornix may be responsible for concussion symptoms, such as LOC, amnesia, and cognitive dysfunction ${ }^{64}$ However, in those instances without LOC, which are the majority, there appeared to be significant forces transmitted to deep midbrain and brainstem structures, which implies a mechanism in which subconcussive injury may also occur.

Broglio et al. examined 95 high school football players across four seasons by using a helmet telemetry system to record the total number of head impacts and the associated acceleration forces. ${ }^{11}$ Results showed that the number of impacts during a 14-week season varied with an athlete's playing position and starting status. The average player sustained 652 impacts (range 5-2235 impacts) during a season. Linemen had the greatest number of impacts per season (868); followed by tight ends, running backs, and linebackers (619); quarterbacks (467); and receivers, cornerbacks, and safeties (372). The seasonal linear acceleration burden averaged $16,746.1 \mathrm{~g}$, whereas the rotational acceleration burden was $1,090,697.7 \mathrm{rad} / \mathrm{sec}^{2}$ These findings indicate that high school football players sustain a high number of head impacts each season, with associated cumulative impact burdens that are equally impressive. ${ }^{11}$ Talavage et al., who used similar technology, found comparable numbers and rates of hit accumulations. ${ }^{79}$ 
Studies have varied in their estimation of the threshold for diagnosed or recognized concussion, both between individual athletes and within the same athlete. One investigation monitored all football-related head impacts in 78 high school athletes (mean age 16.7 years) in the period from 2005 to 2008 to better understand the biomechanical characteristics of concussive impacts. ${ }^{12}$ Fifty-four thousand two hundred forty-seven impacts were recorded, and 13 concussive episodes were captured for analysis. Classification and regression tree analysis of impacts indicated that rotational acceleration $\left(5582.3 \mathrm{rad} / \mathrm{sec}^{2}\right)$, linear acceleration (96.1g), and impact location (front, top, and back) yielded the highest predictive value of concussion. ${ }^{12}$ In general, it is believed that the greatest risk is with a linear acceleration greater than $95 \mathrm{~g}$, rotational acceleration greater than $5500 \mathrm{rad} / \mathrm{sec},{ }^{2}$ and impacts occurring on the top, front, or back of the helmet. ${ }^{11,28}$ The NFL studies showed that while many impacts may exceed $98 g$, this is the threshold for $75 \%$ human tolerance for symptomatic concussion. ${ }^{64}$

Eckner et al. explored the characteristics of 20 concussion-invoking impacts in 19 high school football players, analyzing the total number of head impacts, severity profile values, cumulative linear and rotational acceleration values during the same game or practice session, and 30 -minute and 1-week periods preceding these impacts. ${ }^{24}$ They found that concussions occurred over a wide range of impact magnitudes and that the cumulative impact burden prior to a concussion was not different from that before nonconcussive impacts of greater magnitudes in the same athletes. Therefore, they concluded that an athlete's concussion threshold may be a dynamic feature over time and that there is a lack of cumulative effects of nonconcussive impacts on the concussion threshold. Alternatively, another interpretation of such a study is that the type of impacts occurring in players who sustain a concussion can be no different from those occurring in asymptomatic players, further pointing to the role and potential importance of subconcussive impacts.

Crisco et al. have investigated impact characteristics in collegiate football players. ${ }^{18-20}$ They found that player position and impact location were the most significant factors accounting for differences in head impacts. Running backs and quarterbacks sustained the greatest-magnitude head impacts, whereas linemen and linebackers received the greatest overall number of head impacts. The total number of head impacts was a median of 420 and a maximum of 2492. Prior studies have shown variance in the total number of head impacts in collegiate players from 950 head impacts per season ${ }^{31,32}$ to 1353 per season. ${ }^{72}$

Schnebel et al. used accelerometers embedded in the crown of helmets in both high school and collegiate football players. ${ }^{72}$ The authors found the expected number of high-speed, open-field collisions in skill position athletes, with forces in the range of $90-120 \mathrm{~g}$ and a duration of about $15 \mathrm{msec}$. They, like other researchers, documented a threshold in the range of $60-90 \mathrm{~g}$ (mean $75 \mathrm{~g}$ ) for concussion and asserted that collegiate players tend to have higher-impact accelerations than high school players in similar playing positions. Moreover, the highest-intensity impacts in high school players occurred frequently and at levels greater than $100 g$. However, the most intriguing and unexpected finding in this study was that linemen incur impacts of $20-30 g$ on nearly every play. Given the football tradition of linemen starting every play in the 3-point stance and lunging forward to immediately encounter their opposing player, head contact occurs on a constant and ubiquitous basis. Schnebel and colleagues also noted that linemen experienced high impacts of up to $120 \mathrm{~g}$ forces in 1 out of every 120 plays. $^{72}$ If one were to extrapolate these data to the average number of plays per game, linemen sustain direct head impacts of an average force of $25 \mathrm{~g}$ 45-55 times per game. Further, depending on the style of practice sessions, similar head impact exposure may be seen on a daily basis during both seasonal and spring training periods. However, as Guskiewicz and Mihalik ${ }^{31}$ and others ${ }^{64,72}$ have found, the magnitude of impacts to an opponent's football helmet does not necessarily correlate with the probability of sustaining a concussion or its severity.

Youth football players, generally 7-14 years of age, constitute approximately $70 \%$ of all football players and of 3.5 million participants. Authors of a recent study monitored 7 youth football participants, ages 7 and 8 years, during a football season and noted an average of 107 impacts per player for the season. ${ }^{21}$ Linear accelerations ranged from 10 to $100 \mathrm{~g}$, and rotational accelerations ranged from 52 to $7694 \mathrm{rad} / \mathrm{sec}^{2}$ The majority of the impacts were to the sides (36\%) and front $(31 \%)$ of the helmets, and $61 \%$ occurred during practices. Of these hits, 38 were greater than $40 \mathrm{~g}$ and 6 were greater than $80 \mathrm{~g}$, all occurring at practice sessions. This study was the first to document that very-high-velocity impacts are possible at the youth level of football play. Thus, while youth football players may have fewer helmet impacts and lower-force hits than their older counterparts, high-magnitude impacts may occur nonetheless, and their long-term implications in an exposure paradigm are uncertain.

Neuropsychological Evaluation. In a recent study, Gysland et al. sought to investigate the relationship between subconcussive impacts and concussion history on clinical measures of neurological function. ${ }^{33}$ Before and after a single season 46 collegiate football players completed 5 clinical measures of neurological function commonly used in the evaluation of concussion. These tests included the Automated Neuropsychological Assessment Metrics, Sensory Organization Test, Standardized Assessment of Concussion, Balance Error Scoring System, and Graded Symptom Checklist, and impact data were recorded using the Head Impact Telemetry system. Although each player averaged $1177.3 \pm 772.9$ head impacts over the course of a season, Gysland and colleagues found that they did not demonstrate any clinically meaningful changes from preseason to postseason on the measures of neurological function utilized. ${ }^{33}$ Similar findings were reported in another study of college football players, according to both Sideline Assessment of Concussion and Immediate PostConcussion Assessment and Cognitive Testing scores. ${ }^{50}$ Although there may be a dose response with regard to impacts that must be considered over the course of a player's career, the measures of neurological function used may 
not have been sensitive enough to detect subclinical neurological dysfunction in athletes sustaining many repetitive subconcussive impacts.

However, additional research now suggests that these nonconcussive impacts may not be benign. Killam et al. found that nonconcussed collegiate athletes in contact sports actually scored lower than controls in two memory domains and had lower total scores on the Repeatable Battery for the Assessment of Neuropsychological Status. ${ }^{38}$ Their study was limited by its small sample size as well as its design. The independent groups were established on the basis of self-reported data, which may yield less validity than a more rigorous prospective study design. The retrospective survey design also did not allow for pretesting of cognitive performance, and thus there was no individualized internal standardization. This finding might suggest that the findings could be attributed to selection bias; however, the controls (with which the nonconcussed collegiate athletes were compared) also did not undergo prestudy testing, and there did not appear to be any differences in demographic characteristics including mean grade point average. The authors' data suggest that participation in contact sports may produce subclinical cognitive impairments in the absence of a diagnosable concussion, presumably resulting from the cumulative effects produced by multiple mild head injuries. This and other studies ${ }^{12,72}$ demonstrate that peak acceleration may not be a sufficient measure to predict cognitive deficit and that greater impact forces do not necessarily correlate with a greater likelihood of neurological impairment. Instead, the cumulative number of helmet impacts may become the major criterion of subconcussive burden. The observable neurological signs and symptoms are probably the result of interrupting the communication between complex neural networks, and thus representing a diffuse rather than a focal brain injury.

McAllister et al. studied 214 collegiate Division I football and ice hockey players, analyzing their accelerometer data and neuropsychological outcomes, as compared with those in a control group of athletes in noncontact sports. The authors found that the athletes in contact sports had a worse performance on tests for new learning and that poorer scores on postseason cognitive testing correlated with greater head impact exposure. This worse performance was evident despite the fact that none of the contact-sport athletes had a documented sports concussion during the period of study. ${ }^{46}$ In contrast, Miller et al., who used Standardized Assessment of Concussion and computerized neuropsychological testing in Division III football players, found no difference among preseason baseline, midseason, and postseason assessments in the players who did not sustain a concussion. ${ }^{50}$ Thus, there may be specific neuropsychological metrics that are better suited or more sensitive in detecting the effects of repetitive subconcussion forces. Perhaps the symptoms or sequelae of repetitive subconcussion require a greater amount of time to develop than a single season.

Neuroradiological Findings. The role of neuroimaging in concussion had been a progressive one. While most standard MRI sequences have been designed to evaluate for structural damage at the macroscopic level, recently developed advanced sequences have the potential to increase the sensitivity of MRI to detect both structural and functional abnormalities associated with concussion. This potential exists in the acute setting and, subsequently, in the subacute and chronic phases of recovery. The use of these new techniques is especially relevant in cases in which conventional CT and MRI sequences cannot detect macroscopic structural abnormalities ${ }^{68}$

To test the hypothesis that subconcussive blows cause an accumulation of neurophysiological changes, it is necessary to measure changes in neurological function over time. Talavage and colleagues performed MRI, fMRI, and neurocognitive assessments in a group of high school football players at 3 distinct times: 1) prior to the start of contact practices, 2) during the season, and 3) 2-5 months after the season concluded. ${ }^{79}$ In addition to these assessments, the Head Impact Telemetry system was used to record head collisions during all contact practices and games. In the absence of outwardly observable symptoms of concussion, the athletes demonstrated quantifiable neurophysiological changes on both fMRI studies and Immediate Post-Concussion Assessment and Cognitive Testing. Those players with functionally observed impairment (FOI+) exhibited changes in fMRI activation while performing a working memory task, and these changes were at least as great as those in players in whom a diagnosis of concussion (that is, a clinically observed impairment $[\mathrm{COI}+]$ ) had been made by the team physician (Fig. $1^{10,79}$ ). Of particular interest, the FOI+ group of players was primarily composed of linemen, individuals who experience obligatory helmet-to-helmet contact on nearly every play from the line of scrimmage; the number of blows to the head was the only measure by which this groups' telemetry values differed from those in players with diagnosed concussion or who exhibited no neurophysiological alteration (Table $1^{10}$ ). This finding of neuropsychological disturbance in the absence of classic symptoms of concussion is consistent with prior observations in 7 former NFL offensive linemen and a wide receiver, as reported by Omalu and colleagues and described below. ${ }^{60,61,63}$

A follow-up study by Breedlove et al. demonstrated that the fMRI changes in many regions of the brain statistically correlated with the number and (spatial) distribution of hits received after beginning contact practices. ${ }^{10}$ Critically, regression models constructed to relate the hits experienced to the observed fMRI changes were found to explain an even greater proportion of the variance for the concussed group (COI+) than the asymptomatic group (COI-). The COI- group exhibited substantial hit-correlated involvement of the visual processing systems in the upper parietal and occipital lobes. In contrast, the COI+ group demonstrated significant relationships between the number and locations of hits and the regions involved in verbal working memory. This last observation strongly suggests that the clinical diagnosis of neurological system deficits may depend on which systems have been compromised and that the entire (recent) history of blows to the head plays a causal role in overall neurological changes.

A new study utilizing diffusion tensor imaging highlights the emerging clinical evidence for subconcussive brain injury? Bazarian et al. investigated the ability to 


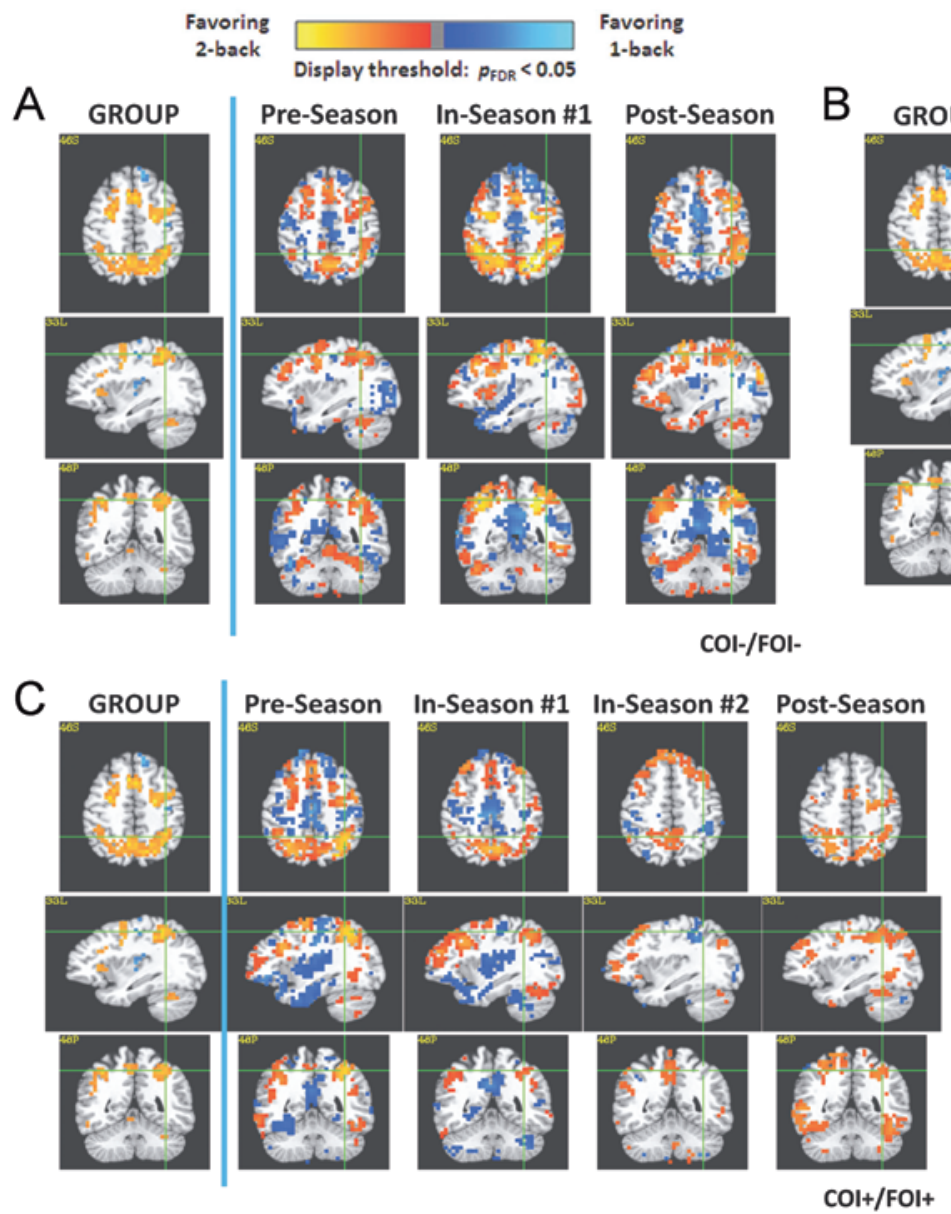

FIG. 1. Magnetic resonance and fMR images obtained in high school football players for baseline purposes prior to the season (preseason), with repeated assessments made during (in-season) and after (postseason) the season. For each group, activation is shown in axial (upper rows), sagittal (center rows), and coronal (lower rows) images intersecting near the left inferior parietal lobule. A: Group COI-/FOI-. Approximately half of the asymptomatic athletes exhibited minimal changes on their in-season fMRI results. B: Group COI-/FOl+. The other half of the asymptomatic athletes exhibited substantial changes on their fMR images. C: Group COI+/FOl+. This finding was on par with changes observed in concussed athletes, although the affected regions differ considerably. Depicted fMRI maps illustrate preferential activation observed in a contrast of a 2-back single letter task (orange-yellow activation) against a 1-back single letter task (blue-cyan activation), both of which were conducted in a single $\mathrm{fMRI}$ run. Changes in direction (or presence/absence) of the contrast are considered meaningful. In-Season \#1 = first assessment during the competition season; In-Season \#2 = second assessment during the competition season.

detect subject-specific changes in brain white matter before and after sports-related concussion. Their prospective cohort study was performed in 9 high school athletes engaged in hockey or football and 6 controls. All 15 subjects underwent diffusion tensor imaging both pre- and postseason within a 3-month interval. Concussion was diagnosed in only 1 athlete (scanned within 72 hours of injury), and 8 suffered between 26 and 399 subconcussive head blows. ${ }^{7}$ Fractional anisotropy and mean diffusivity were measured, and the percentage of white matter voxels with significant $(\mathrm{p}<0.05)$ preseason to postseason changes in these values was highest for the concussed athlete, intermediate for

TABLE 1: Summary statistics for peak translational acceleration and number of helmet impacts over the course of the season in a population of high school football players*

\begin{tabular}{lccc}
\hline \multirow{2}{*}{ Parameter } & \multicolumn{3}{c}{ Group (mean \pm SD; range) } \\
\cline { 2 - 4 } & \multicolumn{1}{c}{ COI-/FOI- } & COI-/FOI+ & COI+/FOI+ \\
\hline peak translational acceleration $(g)$ & $27.5 \pm 16.6 ; 10.0-194.1$ & $27.7 \pm 17.5 ; 10.0-255.6$ & $28.5 \pm 20.1 ; 10.0-279.0$ \\
no. of helmet impacts over the season & $656 \pm 378 ; 226-1463$ & $1090 \pm 570 ; 396-1855$ & $546 \pm 464 ; 218-1551$ \\
\hline
\end{tabular}

* The distributions of peak linear magnitude did not exhibit significant differences, but the number of blows sustained was significantly different. In particular, the COI-/FOI+ group sustained significantly more blows than the COI+/FOI+ group ( $p<0.05$, Tukey-Kramer test). 
those with subconcussive head blows, and lowest for controls. ${ }^{7}$ While analysis detected significantly changed white matter in a single concussed athlete as expected, the most striking findings were in the athletes who did not sustain a concussion. Asymptomatic athletes with multiple subconcussive head blows had abnormalities in a percentage of their white matter that was more than 3 times higher than that in controls. The significance of these white matter changes and their relationship to head impact forces are unknown and will require further studies.

Necropsy Tissue Analysis. The syndrome of CTE, initially described by Omalu et al. in $2005,{ }^{61}$ is now known to occur not only in football players, but also in boxers, wrestlers, hockey players, and even military personnel. ${ }^{49,57-59} \mathrm{It}$ is believed to be a lesser form of injury than dementia pugilistica, initially described by Martland in 1928. Chronic traumatic encephalopathy is defined as a progressive neurodegenerative syndrome caused by episodic and repetitive blunt force impacts to the head and the transfer of acceleration-deceleration forces to the brain. Patients with this disease usually present clinically after a prolonged latent period characterized by a composite syndrome of mood disorders, neuropsychiatric disturbance, and cognitive impairment. Gross brain examination is normal and fails to disclose any area of remote injury, infarction, or atrophy. Direct microscopic brain tissue analysis with tau protein antibody staining reveals multifocal or diffuse tauopathy, which may be associated with low-grade and multifocal white matter rarefaction, microglial activation, and parenchymal histiocytes. Chronic traumatic encephalopathy is characterized by neuronal loss and hyperphosphorylated tau protein deposits in topographic neurofibrillary tangles and neuritic threads, usually without amyloid plaques, involving various areas of the neocortex, subcortical region, basal ganglia, and brainstem. Although amyloid plaques may be seen in a minority of cases, tauopathy is the hallmark histologically. ${ }^{49,57}$

We conducted an autopsy analysis in 8 former professional football players by using detailed and specialized staining techniques for the presence of tau protein (Table 2; unpublished data, 2012). ${ }^{57,59}$ In all cases, similar neurobehavioral, neuropsychiatric, and neuropathological abnormalities consistent with CTE were found. In none of these athletes was concussion a part of the medical or athletic history. Whether methodology at the time was insufficient to detect the presence of a concussion or whether underreporting occurred because of player ignorance or motivation or because of sports cultural issues is unknown. Seven of these football players were linemen, a position that is associated with constant, mandatory, and often gratuitous head-to-head impacts. As reported by Schnebel et al., biophysics data reveal that linemen sustain 20-30g forces to the head on nearly every play. ${ }^{71}$ Thus, our autopsy data and the findings of McKee et al. ${ }^{6,49}$ demonstrate that there is a subset of athletes in contact sports, especially former football players, who do not have a prominent history of known or identified concussions but nonetheless have typical tauopathy on autopsy examination. ${ }^{49,59-63}$ Taken together, these necropsy tissue findings point to subconcussion as a pathophysiological mechanism for unsuspected brain injury in persons exposed to contact sports and/or repetitive explosive blasts through military service.

\section{Discussion}

In recent years, there have been major advances in our understanding of the incidence, biomechanical forces, and cellular responses in mTBI. The amount of laboratory research, both animal-based experiments and investigations into the cellular responses underlying concussion, as well as clinical studies to determine the effects of concussion, has exponentially increased. ${ }^{86}$ In fact, it is now often stated that the mTBI research produced during the past decade supersedes the volume and content of all previous information. An emerging concept is the phenomenon of subconcussive impacts, as new evidence highlights their ubiquity in contact sports and explosive blasts, as well as their potential to contribute to the development of subacute and chronic sequelae such as depression, postconcussive syndrome, posttraumatic stress disorder, mild cognitive impairment, CTE, and dementia pugilistica.

Previous work utilizing survey research from the Center for the Study of Retired Athletes has shown that both mild cognitive impairment and depression are more common than expected in age-matched controls and that a higher incidence is associated with 3 or more concussions. ${ }^{28,29}$ In soccer, it has been suggested that repetitive

TABLE 2: Autopsy analysis of 7 former NFL players*

\begin{tabular}{ccclll}
\hline Case No. & Age (yrs) & $\begin{array}{c}\text { Duration of Professional } \\
\text { Career (yrs) }\end{array}$ & \multicolumn{1}{c}{ Symptoms } & Pathology & Cause of Death \\
\hline 1 & 50 & 17 & Dep, FB, FM, SA & AP, NFTs, NTs & cardiac \\
2 & 45 & 7 & Dep, FB, FM, SA & NFTs, NTs & suicide \\
3 & 45 & 10 & Dep, FB, FM & NFTs, NTs & OD \\
4 & 35 & 10 & Dep, FB, FM & NFTs, NTs & suicide \\
5 & 45 & 12 & Dep, drugs, FM & NFTs, NTs & OD \\
6 & 39 & 7 & Dep, drugs, FM & NFTs, NTs & OD \\
7 & 50 & 10 & Dep, drugs, FM & NFTs, NTs & OD \\
8 & 26 & 5 & Dep, personality changes & NFTs, NTs & fall from vehicle \\
\hline
\end{tabular}

* $\mathrm{AP}=$ amyloid plaque; Dep = depression; FB = failed business; FM = failed marriage; NFT = neurofibrillary tangle; NT = neuritic thread; $\mathrm{OD}=$ overdose; $\mathrm{SA}=$ substance abuse. 
heading of the ball may lead to an increased risk of chronic neurological injury. ${ }^{26,73}$ Studies in Division I college football players have shown that those experiencing 3 or more prior concussions had a triple incidence of subsequent concussions and that those with multiple concussions had more symptoms and took longer to recover. 13,30,46,47 $^{-1}$

As noted previously, Talavage et al. discovered a new category of injured athletes: those with no readily observable symptoms but who instead exhibited functional impairment as measured by neuropsychological testing and fMRI studies. ${ }^{79}$ This "third group" in which abnormal neurological performance occurred despite a lack of symptoms typically associated with a clinically diagnosed concussion may shed light on the issue of subconcussive impacts and their relationship to chronic neurological syndromes (Fig. 2). Subsequent work by the same investigators suggests that it is the accumulation of multiple blows to the head, rather than a single event, that can produce neurological impairments. ${ }^{10}$ Additionally, their work implies that the sequence of blows experienced by a player can mediate the severity of the observed symptoms that lead to the clinical diagnosis of concussion, or the absence thereof (for example, in the case of FOI+). The potential for accumulated damage would also probably involve biochemical factors of the period of cellular vulnerability, a hypermetabolic state, or vascular dysautoregulation as the pathophysiological mechanisms of mTBI. ${ }^{3,76,80,83-85}$

In our laboratory and those of others, rodent models of mTBI have resulted in a significant number of damaged corticospinal tract axons, permeability in the blood-brain barrier, remote effects away from the cortical impact site, and altered neuronal soma. All of these alterations can occur in the absence of behavioral changes. Thus, there is laboratory evidence that subconcussive-level impacts can lead to anatomical and physiological alterations and that they especially occur if the blows are repetitive. Biophys- ics data gathered through football helmet accelerometer studies have shown that youth, high school, and college players may experience a wide range of head impacts, from 100 to over 1000 during the course of a season (Table 3). As stated above, compared with location and magnitude of forces, the cumulative number of head impacts may best correlate with the potential for concussion occurrence or chronic effects. It is uncertain if head impacts have a threshold for magnitude or for number, or both, which could result in a cumulative risk for detrimental effects on brain structures or physiological function.

Our understanding of the issue of subconcussion is further clouded by the marked variability between the thresholds for clinically diagnosed concussion in terms of linear acceleration, rotational acceleration, and location and number of impacts. $7,10,11,18,32,33,50,64,70,72,79$ We stress that not all head impacts should be considered potentially harmful. An athlete's risk of experiencing long-standing effects of repetitive subconcussive blows is probably measured as a cumulative dose over a lifetime and could include factors such as age at exposure, type and magnitude of exposure, recovery periods, differential rates of recovery, genotype, individual vulnerability, and others. The role of protective equipment and the variability in such equipment are also factors that may come into play, but their contribution is unknown. For now, there is a lack of evidence to make a recommendation regarding the number of subconcussive impacts an athlete should sustain prior to ending the athlete's season or career. As our knowledge about this emerging concept continues to evolve, refined and advanced adjunctive measures of assessment may someday help to guide such decisions to decrease the incidence of delayed chronic neurological deficits associated with repetitive subconcussion. For the time being, however, limiting the overall head impact burden as much as possible is the most prudent recommendation for today's athlete.

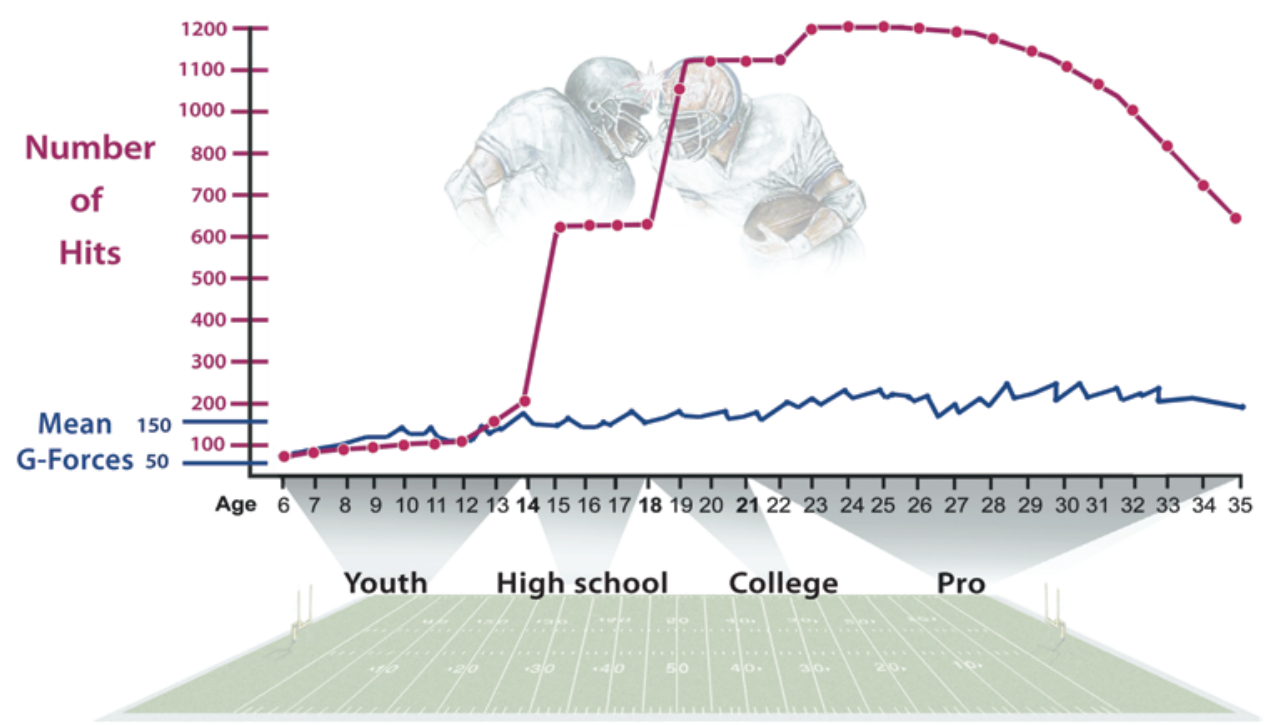

FIG. 2. Graph showing cranial impact exposure in football players of various ages. Biophysics data gathered through football helmet accelerometer studies have shown that youth, high school, and college players may experience a wide range of head impacts, from 100 to over 1000 during the course of a season. As compared with the location and magnitude of forces, the cumulative number of head impacts is likely to best correlate with the potential for concussion occurrence and/or long-standing effects and the development of neurodegenerative disease. 
TABLE 3: Comparison of head impacts in football by level of competition*

\begin{tabular}{|c|c|c|c|}
\hline Authors \& Year & $\begin{array}{c}\text { Level of } \\
\text { Competition }\end{array}$ & $\begin{array}{l}\text { Age } \\
\text { Range } \\
\text { (yrs) }\end{array}$ & $\begin{array}{c}\text { No. of Average } \\
\text { Head Impacts per } \\
\text { Season (range) }\end{array}$ \\
\hline Daniel et al., 2012 & youth & $5-14$ & 107 (NA) \\
\hline $\begin{array}{l}\text { Breedlove et al., } 2012 \\
\text { Broglio et al., } 2011 \\
\text { Eckner et al., } 2011 \\
\text { Schnebel et al., } 2007 \\
\text { Talavage et al., } 2013\end{array}$ & high school & $14-18$ & $625 \dagger(5-2235)$ \\
\hline $\begin{array}{l}\text { Crisco et al., } 2010 \\
\text { Crisco et al., } 2011 \\
\text { Guskiewicz et al., } 2007 \\
\text { Gysland et al., } 2012 \\
\text { Rowson et al., } 2012 \\
\text { Schnebel et al., } 2007\end{array}$ & collegiate & $18-22$ & $1125 †(125-2492)$ \\
\hline extrapolation & professional & $>22$ & $>1200 \ddagger(N A)$ \\
\hline
\end{tabular}

* The number of impacts accrued each season varies by position. NA $=$ not available.

† Head impacts averaged from mean data available from accelerometer studies at each level of competition.

$\ddagger$ Estimate based on practice patterns and style of play.

\section{Conclusions}

There are both established and emerging clinical and laboratory data that indicate that subconcussive impacts to the brain may lead to detrimental effects on neurological function, both short- and long-term, including the potential for chronic neurodegenerative syndromes. Our understanding of these phenomena is still in its infancy and evolving, but will probably determine the ultimate risk for those exposed to repetitive mTBI in athletic endeavors or military service. In the meantime, one strategy for football players may be to minimize exposure to recurring cranial impacts during practice sessions, as Pop Warner Football has recently done at the youth level. ${ }^{55}$ Another possibility is to change styles of play, such as having linemen no longer start in a down stance but instead in a squatting position, to remove them from the inexorable, ubiquitous, gratuitous head contact on every play. It is clear that further research is needed to have a more complete appreciation of the potential for the emerging concept of subconcussive brain injury to ultimately develop potential translational and preventative measures.

\section{Disclosure}

The authors report no conflict of interest concerning the materials or methods used in this study or the findings specified in this paper.

Author contributions to the study and manuscript preparation include the following. Conception and design: Bailes, Petraglia, Omalu. Acquisition of data: Petraglia, Omalu, Nauman, Talavage. Analysis and interpretation of data: Petraglia. Drafting the article: all authors. Critically revising the article: all authors. Reviewed submitted version of manuscript: all authors. Approved the final version of the manuscript on behalf of all authors: Bailes. Administrative/technical/material support: Bailes. Study supervision: Bailes.

\section{References}

1. Allen GV, Gerami D, Esser MJ: Conditioning effects of repetitive mild neurotrauma on motor function in an animal model of focal brain injury. Neuroscience 99:93-105, 2000

2. Bailes JE, Mills JD: Docosahexaenoic acid reduces traumatic axonal injury in a rodent head injury model. J Neurotrauma 27:1617-1624, 2010

3. Barkhoudarian G, Hovda DA, Giza CC: The molecular pathophysiology of concussive brain injury. Clin Sports Med 30: 33-48, vii-viii, 2011

4. Barth JT, Freeman JR, Broshek DK, Varney RN: Acceleration-deceleration sport-related concussion: the gravity of it all. J Athl Train 36:253-256, 2001

5. Bauer JA, Thomas TS, Cauraugh JH, Kaminski TW, Hass CJ: Impact forces and neck muscle activity in heading by collegiate female soccer players. J Sports Sci 19:171-179, 2001

6. Baugh CM, Stamm JM, Riley DO, Gavett BE, Shenton ME, Lin A, et al: Chronic traumatic encephalopathy: neurodegeneration following repetitive concussive and subconcussive brain trauma. Brain Imaging Behav 6:244-254, 2012

7. Bazarian JJ, Zhu T, Blyth B, Borrino A, Zhong J: Subjectspecific changes in brain white matter on diffusion tensor imaging after sports-related concussion. Magn Reson Imaging 30:171-180, 2012

8. Bennett RE, Mac Donald CL, Brody DL: Diffusion tensor imaging detects axonal injury in a mouse model of repetitive closed-skull traumatic brain injury. Neurosci Lett 513:160165,2012

9. Blaylock RL, Maroon J: Immunoexcitotoxicity as a central mechanism in chronic traumatic encephalopathy-a unifying hypothesis. Surg Neurol Int 2:107, 2011

10. Breedlove EL, Robinson M, Talavage TM, Morigaki KE, Yoruk U, O'Keefe K, et al: Biomechanical correlates of symptomatic and asymptomatic neurophysiological impairment in high school football. J Biomech 45:1265-1272, 2012

11. Broglio SP, Eckner JT, Martini D, Sosnoff JJ, Kutcher JS, Randolph C: Cumulative head impact burden in high school football. J Neurotrauma 28:2069-2078, 2011

12. Broglio SP, Schnebel B, Sosnoff JJ, Shin S, Fend X, He X, et al: Biomechanical properties of concussions in high school football. Med Sci Sports Exerc 42:2064-2071, 2010

13. Collins MW, Grindel SH, Lovell MR, Dede DE, Moser DJ, Phalin BR, et al: Relationship between concussion and neuropsychological performance in college football players. JAMA 282:964-970, 1999

14. Conte V, Uryu K, Fujimoto S, Yao Y, Rokach J, Longhi L, et al: Vitamin $\mathrm{E}$ reduces amyloidosis and improves cognitive function in $\mathrm{Tg} 2576$ mice following repetitive concussive brain injury. J Neurochem 90:758-764, 2004

15. Covassin T, Elbin RJ: The female athlete: the role of gender in the assessment and management of sport-related concussion. Clin Sports Med 30:125-131, x, 2011

16. Creed JA, DiLeonardi AM, Fox DP, Tessler AR, Raghupathi $\mathrm{R}$ : Concussive brain trauma in the mouse results in acute cognitive deficits and sustained impairment of axonal function. J Neurotrauma 28:547-563, 2011

17. Creeley CE, Wozniak DF, Bayly PV, Olney JW, Lewis LM: Multiple episodes of mild traumatic brain injury result in impaired cognitive performance in mice. Acad Emerg Med 11:809-819, 2004

18. Crisco JJ, Fiore R, Beckwith JG, Chu JJ, Brolinson PG, Duma $\mathrm{S}$, et al: Frequency and location of head impact exposures in individual collegiate football players. J Athl Train 45:549559,2010

19. Crisco JJ, Wilcox BJ, Beckwith JG, Chu JJ, Duhaime AC, Rowson S, et al: Head impact exposure in collegiate football players. J Biomech 44:2673-2678, 2011

20. Crisco JJ, Wilcox BJ, Machan JT, McAllister TW, Duhaime 
AC, Duma SM, et al: Magnitude of head impact exposures in individual collegiate football players. J Appl Biomech 28: 174-183, 2012

21. Daniel RW, Rowson S, Duma SM: Head impact exposure in youth football. Ann Biomed Eng 40:976-981, 2012

22. Dashnaw ML, Petraglia AL, Bailes JE: An overview of the basic science of concussion and subconcussion: where we are and where we are going. Neurosurg Focus 33(6):E5, 2012

23. DeFord SM, Wilson MS, Rice AC, Clausen T, Rice LK, Barabnova A, et al: Repeated mild brain injuries result in cognitive impairment in B6C3F1 mice. J Neurotrauma 19:427-438, 2002

24. Eckner JT, Sabin M, Kutcher JS, Broglio SP: No evidence for a cumulative impact effect on concussion injury threshold. J Neurotrauma 28:2079-2090, 2011

25. Friess SH, Ichord RN, Ralston J, Ryall K, Helfaer MA, Smith C, et al: Repeated traumatic brain injury affects composite cognitive function in piglets. J Neurotrauma 26:1111-1121, 2009

26. Fuller CW, Ekstrand J, Junge A, Andersen TE, Bahr R, Dvorak J, et al: Consensus statement on injury definitions and data collection procedures in studies of football (soccer) injuries. Clin J Sport Med 16:97-106, 2006

27. Gavett BE, Stern RA, McKee AC: Chronic traumatic encephalopathy: a potential late effect of sport-related concussive and subconcussive head trauma. Clin Sports Med 30:179-188, xi, 2011

28. Guskiewicz KM, Marshall SW, Bailes J, McCrea M, Cantu $\mathrm{RC}$, Randolph C, et al: Association between recurrent concussion and late-life cognitive impairment in retired professional football players. Neurosurgery 57:719-726, 2005

29. Guskiewicz KM, Marshall SW, Bailes J, McCrea M, Harding HP Jr, Matthews A, et al: Recurrent concussion and risk of depression in retired professional football players. Med Sci Sports Exerc 39:903-909, 2007

30. Guskiewicz KM, McCrea M, Marshall SW, Cantu RC, Randolph C, Barr W, et al: Cumulative effects associated with recurrent concussion in collegiate football players: the NCAA Concussion Study. JAMA 290:2549-2555, 2003

31. Guskiewicz KM, Mihalik JP: Biomechanics of sport concussion: quest for the elusive injury threshold. Exerc Sport Sci Rev 39:4-11, 2011

32. Guskiewicz KM, Mihalik JP, Shankar V, Marshall SW, Crowell DH, Oliaro SM, et al: Measurement of head impacts in collegiate football players: relationship between head impact biomechanics and acute clinical outcome after concussion. Neurosurgery 61:1244-1253, 2007

33. Gysland SM, Mihalik JP, Register-Mihalik JK, Trulock SC, Shields EW, Guskiewicz KM: The relationship between subconcussive impacts and concussion history on clinical measures of neurologic function in collegiate football players. Ann Biomed Eng 40:14-22, 2012

34. Hootman JM, Dick R, Agel J: Epidemiology of collegiate injuries for 15 sports: summary and recommendations for injury prevention initiatives. J Athl Train 42:311-319, 2007

35. Johnson GV, Greenwood JA, Costello AC, Troncoso JC: The regulatory role of calmodulin in the proteolysis of individual neurofilament proteins by calpain. Neurochem Res 16:869873,1991

36. Kanayama G, Takeda M, Niigawa H, Ikura Y, Tamii H, Taniguchi N, et al: The effects of repetitive mild brain injury on cytoskeletal protein and behavior. Methods Find Exp Clin Pharmacol 18:105-115, 1996

37. Kane MJ, Angoa-Pérez M, Briggs DI, Viano DC, Kreipke CW, Kuhn DM: A mouse model of human repetitive mild traumatic brain injury. J Neurosci Methods 203:41-49, 2012

38. Killam C, Cautin RL, Santucci AC: Assessing the enduring residual neuropsychological effects of head trauma in college athletes who participate in contact sports. Arch Clin Neuropsychol 20:599-611, 2005
39. Lado WE, Persinger MA: Mechanical impacts to the skulls of rats produce specific deficits in maze performance and weight loss: evidence for apoptosis of cortical neurons and implications for clinical neuropsychology. Percept Mot Skills 97: 1115-1127, 2003

40. Laurer HL, Bareyre FM, Lee VM, Trojanowski JQ, Longhi L, Hoover R, et al: Mild head injury increasing the brain's vulnerability to a second concussive impact. J Neurosurg 95: 859-870, 2001

41. Lifshitz J, Lisembee AM: Neurodegeneration in the somatosensory cortex after experimental diffuse brain injury. Brain Struct Funct 217:49-61, 2012

42. Longhi L, Saatman KE, Fujimoto S, Raghupathi R, Meaney DF, Davis J, et al: Temporal window of vulnerability to repetitive experimental concussive brain injury. Neurosurgery 56: 364-374, 2005

43. Mata M, Staple J, Fink DJ: Changes in intra-axonal calcium distribution following nerve crush. J Neurobiol 17:449-467, 1986

44. Maxwell WL, McCreath BJ, Graham DI, Gennarelli TA: Cytochemical evidence for redistribution of membrane pump calcium-ATPase and ecto-Ca-ATPase activity, and calcium influx in myelinated nerve fibres of the optic nerve after stretch injury. J Neurocytol 24:925-942, 1995

45. Maxwell WL, Povlishock JT, Graham DL: A mechanistic analysis of nondisruptive axonal injury: a review. J Neurotrauma 14:419-440, 1997

46. McAllister TW, Flashman LA, Maerlender A, Greenwald RM, Beckwith JG, Tosteson TD, et al: Cognitive effects of one season of head impacts in a cohort of collegiate contact sport athletes. Neurology 78:1777-1784, 2012

47. McCrea M, Guskiewicz KM, Marshall SW, Barr W, Randolph $\mathrm{C}$, Cantu RC, et al: Acute effects and recovery time following concussion in collegiate football players: the NCAA Concussion Study. JAMA 290:2556-2563, 2003

48. McCrory P, Meeuwisse W, Johnston K, Dvorak J, Aubry M, Molloy M, et al: Consensus statement on concussion in sport: the 3rd International Conference on Concussion in Sport held in Zurich, November 2008. J Athl Train 44:434-448, 2009

49. McKee AC, Cantu RC, Nowinski CJ, Hedley-Whyte ET, Gavett BE, Budson AE, et al: Chronic traumatic encephalopathy in athletes: progressive tauopathy after repetitive head injury. J Neuropathol Exp Neurol 68:709-735, 2009

50. Miller JR, Adamson GJ, Pink MM, Sweet JC: Comparison of preseason, midseason, and postseason neurocognitive scores in uninjured collegiate football players. Am J Sports Med 35:1284-1288, 2007

51. Mills JD, Bailes JE, Sedney CL, Hutchins H, Sears B: Omega-3 fatty acid supplementation and reduction of traumatic axonal injury in a rodent head injury model. Laboratory investigation. J Neurosurg 114:77-84, 2011

52. Mills JD, Bailes JE, Turner RC, Dodson SC, Sakai J, Maroon JC: Anabolic steroids and head injury. Neurosurgery 70:205210, 2012

53. Mills JD, Hadley K, Bailes JE: Dietary supplementation with the omega-3 fatty acid docosahexaenoic acid in traumatic brain injury. Neurosurgery 68:474-481, 2011

54. Nakajima Y, Horiuchi Y, Kamata H, Yukawa M, Kuwabara M, Tsubokawa T: Distinct time courses of secondary brain damage in the hippocampus following brain concussion and contusion in rats. Tohoku J Exp Med 221:229-235, 2010

55. O'Connor A: Trying to reduce head injuries, youth football limits practices. New York Times. June 13, 2012. (http:// www.nytimes.com/2012/06/14/sports/pop-warner-footballlimits-contact-in-practices.html) [Accessed July 16, 2013]

56. Olsson Y, Rinder L, Lindgren S, Stålhammar D: Studies on vascular permeability changes in experimental brain concussion. 3. A comparison between the effects of single and repeated sudden mechanical loading of the brain. Acta Neuropathol 19:225-233, 1971 
57. Omalu B, Bailes J, Hamilton RL, Kamboh MI, Hammers J, Case M, et al: Emerging histomorphologic phenotypes of chronic traumatic encephalopathy in American athletes. Neurosurgery 69:173-183, 2011

58. Omalu B, Hammers JL, Bailes J, Hamilton RL, Kamboh MI, Webster G, et al: Chronic traumatic encephalopathy in an Iraqi war veteran with posttraumatic stress disorder who committed suicide. Neurosurg Focus 31(5):E3, 2011

59. Omalu BI, Bailes J, Hammers JL, Fitzsimmons RP: Chronic traumatic encephalopathy, suicides and parasuicides in professional American athletes: the role of the forensic pathologist. Am J Forensic Med Pathol 31:130-132, 2010

60. Omalu BI, DeKosky ST, Hamilton RL, Minster RL, Kamboh MI, Shakir AM, et al: Chronic traumatic encephalopathy in a national football league player: part II. Neurosurgery 59: 1086-1093, 2006

61. Omalu BI, DeKosky ST, Minster RL, Kamboh MI, Hamilton RL, Wecht CH: Chronic traumatic encephalopathy in a National Football League player. Neurosurgery 57:128-134, 2005

62. Omalu BI, Fitzsimmons RP, Hammers J, Bailes J: Chronic traumatic encephalopathy in a professional American wrestler. J Forensic Nurs 6:130-136, 2010

63. Omalu BI, Hamilton RL, Kamboh MI, DeKosky ST, Bailes J: Chronic traumatic encephalopathy (CTE) in a National Football League player: case report and emerging medicolegal practice questions. J Forensic Nurs 6:40-46, 2010

64. Pellman EJ, Viano DC, Tucker AM, Casson IR, Waeckerle JF: Concussion in professional football: reconstruction of game impacts and injuries. Neurosurgery 53:799-814, 2003

65. Petraglia AL, Maroon JC, Bailes JE: From the field of play to the field of combat: a review of the pharmacological management of concussion. Neurosurgery 70:1520-1533, 2012

66. Pettus EH, Povlishock JT: Characterization of a distinct set of intra-axonal ultrastructural changes associated with traumatically induced alteration in axolemmal permeability. Brain Res 722:1-11, 1996

67. Povlishock JT, Pettus EH: Traumatically induced axonal damage: evidence for enduring changes in axolemmal permeability with associated cytoskeletal change. Acta Neurochir Suppl 66:81-86, 1996

68. Prabhu SP: The role of neuroimaging in sport-related concussion. Clin Sports Med 30:103-114, ix, 2011

69. Raghupathi R, Mehr MF, Helfaer MA, Margulies SS: Traumatic axonal injury is exacerbated following repetitive closed head injury in the neonatal pig. J Neurotrauma 21:307-316, 2004

70. Rowson S, Duma SM, Beckwith JG, Chu JJ, Greenwald RM, Crisco JJ, et al: Rotational head kinematics in football impacts: an injury risk function for concussion. Ann Biomed Eng 40:113,2012

71. Saatman KE, Abai B, Grosvenor A, Vorwerk CK, Smith DH, Meaney DF: Traumatic axonal injury results in biphasic calpain activation and retrograde transport impairment in mice. J Cereb Blood Flow Metab 23:34-42, 2003

72. Schnebel B, Gwin JT, Anderson S, Gatlin R: In vivo study of head impacts in football: a comparison of National Collegiate Athletic Association Division I versus high school impacts. Neurosurgery 60:490-496, 2007

73. Scott Delaney J, Puni V, Rouah F: Mechanisms of injury for concussions in university football, ice hockey, and soccer: a pilot study. Clin J Sport Med 16:162-165, 2006

74. Shitaka Y, Tran HT, Bennett RE, Sanchez L, Levy MA, Dikranian $\mathrm{K}$, et al: Repetitive closed-skull traumatic brain injury in mice causes persistent multifocal axonal injury and microglial reactivity. J Neuropathol Exp Neurol 70:551-567, 2011

75. Shultz SR, MacFabe DF, Foley KA, Taylor R, Cain DP: Sub- concussive brain injury in the Long-Evans rat induces acute neuroinflammation in the absence of behavioral impairments. Behav Brain Res 229:145-152, 2012

76. Signoretti S, Vagnozzi R, Tavazzi B, Lazzarino G: Biochemical and neurochemical sequelae following mild traumatic brain injury: summary of experimental data and clinical implications. Neurosurg Focus 29(5):E1, 2010

77. Smith DW, Bailes JE, Fisher JA, Robles J, Turner RC, Mills JD: Internal jugular vein compression mitigates traumatic axonal injury in rat model by reducing intracranial slosh effect. Neurosurgery 70:740-746, 2012

78. Spain A, Daumas S, Lifshitz J, Rhodes J, Andrews PJ, Horsburgh K, et al: Mild fluid percussion injury in mice produces evolving selective axonal pathology and cognitive deficits relevant to human brain injury. J Neurotrauma 27:1429-1438, 2010

79. Talavage TM, Nauman E, Breedlove EL, Yoruk U, Dye AE, Morigaki K, et al: Functionally-detected cognitive impairment in high school football players without clinically-diagnosed concussion. J Neurotrauma [epub ahead of print], 2013

80. Tavazzi B, Vagnozzi R, Signoretti S, Amorini AM, Belli A, Cimatti M, et al: Temporal window of metabolic brain vulnerability to concussions: oxidative and nitrosative stresses-part II. Neurosurgery 61:390-396, 2007

81. Tierney RT, Sitler MR, Swanik CB, Swanik KA, Higgins M, Torg J: Gender differences in head-neck segment dynamic stabilization during head acceleration. Med Sci Sports Exerc 37:272-279, 2005

82. Uryu K, Laurer H, McIntosh T, Praticò D, Martinez D, Leight $\mathrm{S}$, et al: Repetitive mild brain trauma accelerates Abeta deposition, lipid peroxidation, and cognitive impairment in a transgenic mouse model of Alzheimer amyloidosis. J Neurosci 22: 446-454, 2002

83. Vagnozzi R, Signoretti S, Cristofori L, Alessandrini F, Floris $\mathrm{R}$, Isgrò $\mathrm{E}$, et al: Assessment of metabolic brain damage and recovery following mild traumatic brain injury: a multicentre, proton magnetic resonance spectroscopic study in concussed patients. Brain 133:3232-3242, 2010

84. Vagnozzi R, Signoretti S, Tavazzi B, Floris R, Ludovici A, Marziali S, et al: Temporal window of metabolic brain vulnerability to concussion: a pilot $1 \mathrm{H}-$ magnetic resonance spectroscopic study in concussed athletes-part III. Neurosurgery 62:1286-1296, 2008

85. Vagnozzi R, Tavazzi B, Signoretti S, Amorini AM, Belli A, Cimatti M, et al: Temporal window of metabolic brain vulnerability to concussions: mitochondrial-related impairmentpart I. Neurosurgery 61:379-389, 2007

86. Weber JT: Experimental models of repetitive brain injuries. Prog Brain Res 161:253-261, 2007

87. Weitbrecht WU, Noetzel H: [Autoradiographic investigations in repeated experimental brain concussion (author's transl).] Arch Psychiatr Nervenkr 223:59-68, 1976 (Ger)

88. Yoshiyama Y, Uryu K, Higuchi M, Longhi L, Hoover R, Fujimoto $\mathrm{S}$, et al: Enhanced neurofibrillary tangle formation, cerebral atrophy, and cognitive deficits induced by repetitive mild brain injury in a transgenic tauopathy mouse model. J Neurotrauma 22:1134-1141, 2005

Manuscript submitted September 21, 2012

Accepted July 15, 2013.

Please include this information when citing this paper: published online August 23, 2013; DOI: 10.3171/2013.7.JNS121822.

Address correspondence to: Julian E. Bailes, M.D., Department of Neurosurgery, NorthShore University Health System, University of Chicago Pritzker School of Medicine, 2650 Ridge Ave., Kellogg 3rd Floor, Evanston, IL 60201. email: jbailes@ northshore.org. 